\title{
Constitutive IKK2 activation in acinar cells is sufficient to induce pancreatitis in vivo
}

\author{
Bernd Baumann, ${ }^{1}$ Martin Wagner, ${ }^{2}$ Tamara Aleksic, ${ }^{2}$ Götz von Wichert, ${ }^{2}$ \\ Christoph K. Weber, ${ }^{2}$ Guido Adler, ${ }^{2}$ and Thomas Wirth ${ }^{1}$
}

1Institute of Physiological Chemistry and 2Department of Internal Medicine I, University of Ulm, Ulm, Germany.

\begin{abstract}
Activation of the inhibitor of NF- $\kappa B$ kinase/NF- $\kappa B(I K K / N F-\kappa B)$ system and expression of proinflammatory mediators are major events in acute pancreatitis. However, the in vivo consequences of IKK activation on the onset and progression of acute pancreatitis remain unclear. Therefore, we modulated IKK activity conditionally in pancreatic acinar cells. Transgenic mice expressing the reverse tetracycline-responsive transactivator (rtTA) gene under the control of the rat elastase promoter were generated to mediate acinar cell-specific expression of IKK2 alleles. Expression of dominant-negative IKK2 ameliorated cerulein-induced pancreatitis but did not affect activation of trypsin, an initial event in experimental pancreatitis. Notably, expression of constitutively active IKK2 was sufficient to induce acute pancreatitis. This acinar cell-specific phenotype included edema, cellular infiltrates, necrosis, and elevation of serum lipase levels as well as pancreatic fibrosis. IKK2 activation caused increased expression of known NF- $\kappa B$ target genes, including mediators of the inflammatory response such as TNF- $\alpha$ and ICAM-1. Indeed, inhibition of TNF- $\alpha$ activity identified this cytokine as an important effector of IKK2-induced pancreatitis. Our data identify the IKK/NF- $K B$ pathway in acinar cells as being key to the development of experimental pancreatitis and the major factor in the inflammatory response typical of this disease.
\end{abstract}

\section{Introduction}

The NF- $\kappa \mathrm{B}$ transcription factors play a prominent role in controlling the integration of innate immunity into the inflammatory response and adaptive immunity. The activation and nuclear translocation of NF- $\kappa \mathrm{B}$ induces the expression of a diverse range of proinflammatory genes, including chemokines, cytokines, and cell adhesion molecules, all necessary for an effective defense response to infectious agents. However, failure to terminate or resolve the inflammatory response has detrimental consequences for the organism. As NF- $\mathrm{KB}$ is one of the main transcriptional regulators of inflammation, pathological activation of NF- $\mathrm{KB}$ is often associated with chronic inflammatory diseases like rheumatoid arthritis, inflammatory bowel disease, asthma, and multiple sclerosis (1-3).

NF-кB represents a family of homodimeric and heterodimeric transcription factors composed of 5 members, namely p50, p52, RelA/p65, RelB, and c-Rel. NF- $\mathrm{B}$ is activated by a large number of inducers, including factors critically involved in the inflammatory response such as TNF- $\alpha$, IL- $1 \beta$, and microbial products. These factors activate the TNF, IL-1, Nod-like, and Toll-like receptor systems and thereby initiate signaling cascades that converge on the

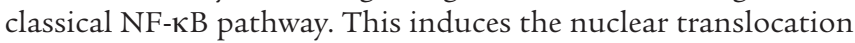
of NF- $\mathrm{KB}$ dimers typically composed of p50 and RelA/p65. The pivotal regulatory step in this pathway is the signal-induced phos-

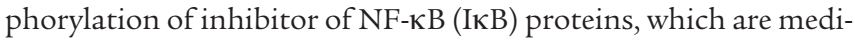

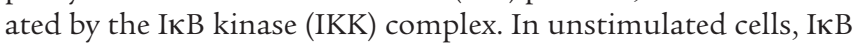
proteins interact with the NF- $\kappa B$ proteins and inhibit their nuclear

Nonstandard abbreviations used: Dox, doxycycline; Ela, elastase; IкB, inhibitor of

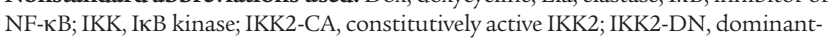
negative IKK2; NEMO, NF-KB essential modulator; rtTA, reverse tetracycline-responsive transactivator.

Conflict of interest: The authors have declared that no conflict of interest exists. Citation for this article: J. Clin. Invest. 117:1502-1513 (2007). doi:10.1172/JCI30876 translocation and DNA binding. The IKK complex is composed of at least 3 distinct polypeptides: the scaffold and regulatory component NF- $\mathrm{KB}$ essential modulator (NEMO; also referred to as IKK $\gamma$ ) and 2 catalytic subunits, IKK1 and IKK2. Both IKK1 and IKK 2 can phosphorylate IKB proteins in vitro. However, a genetic study has shown that in the classical pathway in particular, NEMO and IKK2 are important for the phosphorylation of NF-кB-bound

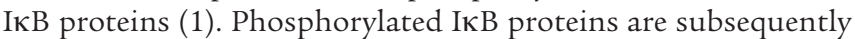
ubiquitinated and degraded by the proteasome. Consequently, NF-אB dimers are released from their inactive cytosolic state, enter the nucleus, and induce transcription of target genes (4).

Proinflammatory target genes include TNFA, IL1B, IL6, INOS, COX2, and ICAM1. These proteins induce a positive feedback loop potentiating and perpetuating the inflammatory response. This could be one of the reasons for the development of chronic inflammatory diseases. In addition to the classical pathway, which depends on IKK2 function, an alternative pathway of NF-KB activation exists. This pathway is activated by certain members of the TNF superfamily (e.g., CD40 ligand, lymphotoxin- $\beta$, and B cell-activating factor of the TNF family) and LPS and involves the upstream kinase NF- $\mathrm{KB}$-inducing kinase, which predominantly activates IKK1 independently of NEMO and IKK2. IKK1 phosphorylates the 100 precursor protein and induces processing to p52. This results in the nuclear translocation of RelB/p52 dimers, which activate a specific set of genes involved in B cell development and lymphoid organogenesis (5).

Acute pancreatitis is initiated in the acinar cells and is characterized by local pancreatic inflammation with recruitment of leukocytes. Several lines of evidence from experimental models suggest that premature activation of trypsinogen represents a critical initiating event that leads to acinar cell damage, tissue destruction, and self digestion of the organ $(6,7)$. The disease is frequently a mild, self-limiting, edematous pancreatitis. However, severe pancreatitis is characterized by high mortality as a result of the uncontrolled 
A

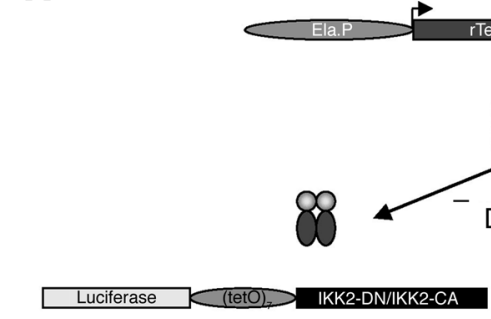

B

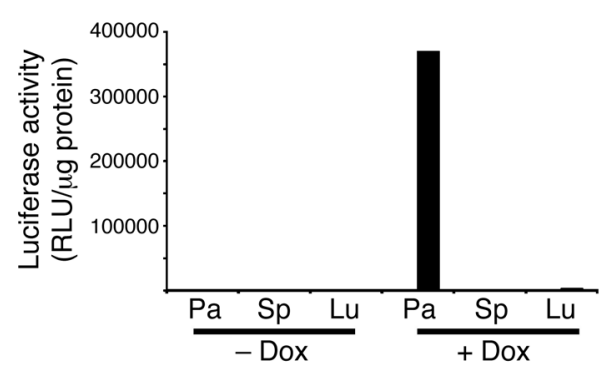

D

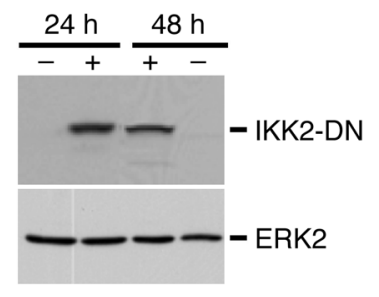

Figure 1

Mouse model for conditional regulation of IKK activity in pancreatic acinar cells. (A) Transgenic approach for Doxregulated expression of IKK2-CA and IKK2-DN in the exocrine pancreas. The Ela promoter (Ela.P) controls the expression of rtTA. In the presence of Dox the rtTA protein binds to the bidirectional promoter (tetO) ${ }_{7}$ and activates the transcription (arrowheads) of luciferase and either IKK2-DN or IKK2-CA. rTetR, reverse tetracycline repressor; VP16, herpes simplex protein. (B) Luciferase activity was measured in pancreas $(\mathrm{Pa})$, spleen $(\mathrm{Sp})$, and lung (Lu) of double-transgenic Ela.rtTAxIKK2-DN mice without Dox or 24 hours after Dox application i.p. Results were expressed as relative light units (RLU) per $\mu$ g protein. (C) In vivo imaging of luciferase activity in double-transgenic Ela.rtTA×IKK2-DN mice (Ela.DN $2 \times T g$ ) showing restricted luciferase expression to the pancreatic region 24 hours after Dox application. (D) IKK2-DN transgene expression was monitored by immunoblot in pancreatic extracts of Ela.rtTAxIKK2-DN mice 24 and 48 hours after Dox application or in uninduced Ela.rtTA $\times$ IKK2-DN controls. ERK2 served as loading control. (E) IKK2 kinase assay (KA) with isolated acini from Dox-treated Ela.rtTAxIKK2-DN mice and single-transgenic IKK2-DN control mice (DN $1 \times \mathrm{Tg}$ ) treated in vitro with cerulein (2 hours) showed decreased IKK activity in Ela.rtTAxIKK2-DN compared with single-transgenic IKK2-DN mice. GST, glutathione-S-transferase. systemic inflammatory response syndrome (SIRS) and multiple organ failure. Although the molecular mechanisms of the pathophysiology are not completely understood, data from experimental pancreatitis models strongly imply that the release of proinflammatory mediators by acinar cells and the recruitment of immune cells are crucial events in the induction of SIRS (8). The relationship between the pancreatic injury and this uncontrolled systemic inflammation remains poorly understood.

The pathophysiology of acute pancreatitis was studied extensively with different animal models such as that of secretagogue hyperstimulation (cerulein model) and several duct ligation models as well as that induced by dibutyltin dichloride (DBTC) (9-13). The cerulein model serves as a paradigm for the initiating event of acute edematous pancreatitis and represents the best-characterized model of the disease to date. It is currently accepted that changes in local $\mathrm{Ca}^{2+}$ signaling, intracellular activation of trypsinogen, and disruption of cellular integrity are the initial events in this model (6). At the molecular basis this is accompanied by activation of the NF- $\mathrm{KB}$ signaling cascade and release of proinflammatory signals (14).

The local inflammation of the pancreas is associated with the production of proinflammatory chemokines and cytokines such as MCP-1, TNF- $\alpha$, IL-1 $\beta$, and IL- 6 as well as of adhesion molecules such as ICAM-1. Mounting evidence suggests that acinar cells are capable to synthesize at least a subset of these proinflammatory factors (15-17). In addition, invading immune cells contribute to the local increase of proinflammatory cytokines. Evidence from experimental models using genetically modified animals suggests that blocking the TNF- $\alpha$ and IL- $1 \beta$ signaling cascades ameliorates pancreatitis (18). The major difficulty in the interpretation of these findings is the open question of the cellular source of the proinflammatory signals and the pathophysiological consequences of the local increase of these factors. The NF-кB-controlled expression of various proinflammatory mediators (e.g., TNFA, IL1B, and ICAM1) strongly argues for a central role of this transcription factor in the regulation of inflammatory processes during acute pancreatitis (14). However, the specific role of NF- $\kappa B$ in acute pancreatitis remains the subject of debate. Conflicting findings using pharmacological inhibitors of the NF- $\kappa \mathrm{B}$ signaling cascade and ectopic pancreatic NF- $\kappa B$ activation were reported $(19,20)$. Therefore, it remains to be determined whether the activation of the IKK/NF- $\mathrm{KB}$ pathway initiates a protective program or promotes inflammation and tissue damage in experimental pancreatitis. Addressing this issue requires the ability to specifically and efficiently modulate NF- $\mathrm{\kappa B}$ activity in animal models of pancreatitis. In a previous study we examined the role of the IKK/NF- $\mathrm{KB}$ system in pancreatitis using a transgenic animal model based on the tetracycline-driven expression of constitutively active IKK2 (IKK2-CA) (21). This system allowed moderate IKK2 activation under the control of the CMV promoter and resulted in the infiltration of immune cells in the pancreas. In this model, we observed increased pancreatic tissue damage when the cerulein model of pancreatitis was applied, suggesting deleterious effects of elevated IKK2 activity. These findings prompted us to analyze the function of IKK2 activation in the course of pancreatitis in more detail.

In the current study we describe the generation of mouse models, which we believe to be novel, that allowed the highly efficient conditional activation and the suppression of IKK activity selectively in 
A

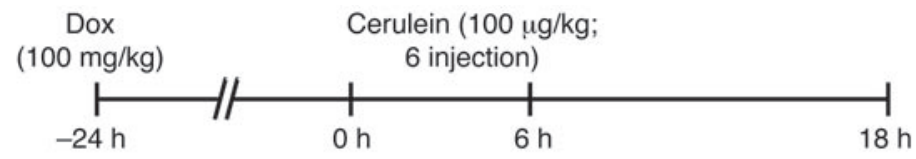

B
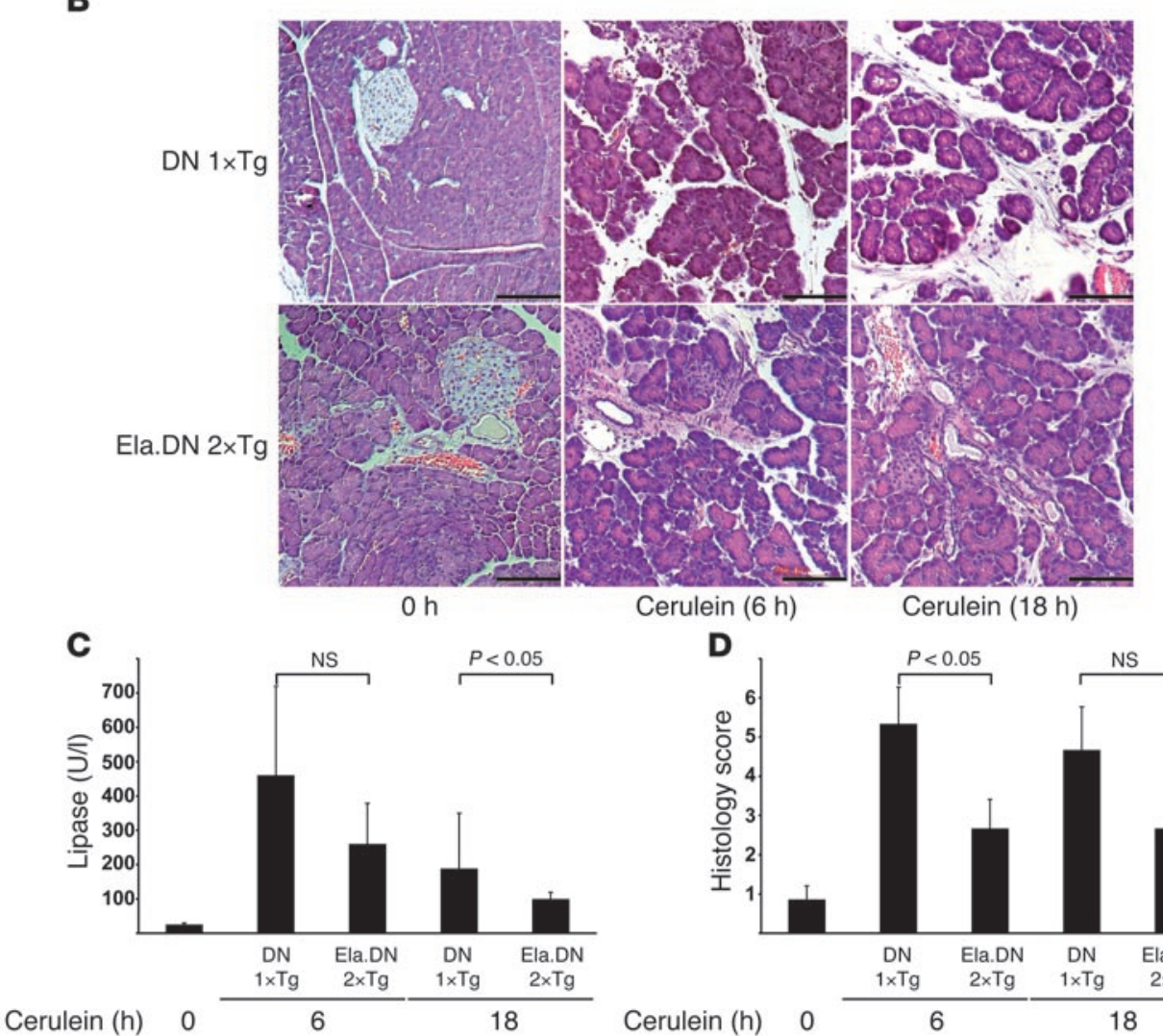

Cerulein $(6 \mathrm{~h})$

D

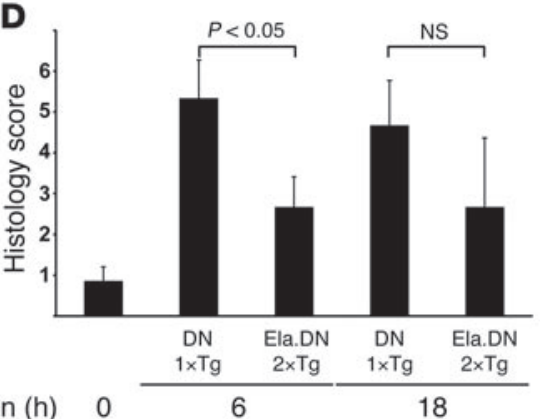

\section{Figure 2}

Cerulein-induced pancreatitis is ameliorated in Ela.rtTAxIKK2-DN mice. (A) Experimental design. Mice were pretreated with Dox 24 hours before induction of pancreatitis through repeated cerulein injections. (B) Morphological examination of Ela.rtTAxIKK2-DN and single-transgenic IKK2-DN controls revealed comparable histology 24 hours after Dox injection (0 hours). Whereas cerulein induced pancreatitis in controls 6 and 18 hours after starting cerulein injections, this phenotype was reduced in Ela.rtTAxIKK2-DN mice. Scale bars: $50 \mu \mathrm{m}$. (C) Serum lipase values were reduced in Ela.rtTAxIKK2-DN compared with controls 6 and 18 hours after starting cerulein injections. (D) Histological score improved in Ela.rtTAxIKK2-DN mice compared with controls during the observation period. (E) Immunoblot confirmed overexpression of IKK2-DN in Ela.rtTAxIKK2-DN mice compared with controls. ERK2 served as a loading control.

\section{E

\begin{tabular}{|c|c|c|c|}
\hline \multicolumn{2}{|c|}{ Cerulein $(6 \mathrm{~h})$} & \multicolumn{2}{|c|}{ Cerulein $(18 \mathrm{~h})$} \\
\hline $\begin{array}{c}\mathrm{DN} \\
1 \times \mathrm{Tg}\end{array}$ & $\begin{array}{c}\text { Ela.DN } \\
2 \times \mathrm{Tg}\end{array}$ & $\begin{array}{c}\mathrm{DN} \\
1 \times \mathrm{Tg}\end{array}$ & $\begin{array}{l}\text { Ela.DN } \\
2 \times T g\end{array}$ \\
\hline & - & & - \\
\hline
\end{tabular}

acinar cells of the pancreas. We provide evidence that ectopic IKK2 activation induced acute pancreatitis, whereas repression of IKK activity attenuated cerulein-mediated pancreatitis. Increased expression of TNF- $\alpha$ was found to be critical for the onset of IKK2-CAinduced pancreatitis.

\section{Results}

Conditional deregulation of IKK activity in pancreatic acinar cells. We addressed the role of the IKK/NF- $\mathrm{KB}$ signaling pathway in acute pancreatitis in vivo using a tetracycline-inducible system. This strategy allowed for the conditional regulation of IKK2 activity selectively in acinar cells of adult mice. We generated transgenic mice expressing the reverse tetracycline-responsive transactivator (rtTA) under the control of the proximal rat elastase (Ela) promoter (Ela.rtTA mice; Figure 1A). These mice were crossed to transgenic mice carrying either the luciferase-(tetO) 7 -IKK2-CA or the luciferase-(tetO) $)_{7}$-dominant-negative IKK2 [luciferase(tetO) $\left.)_{7}-\mathrm{IKK} 2-\mathrm{DN}\right]$ transgene cassettes (22). In double-transgenic
Ela.rtTA $\times$ IKK2-CA and Ela.rtTA $\times$ IKK2-DN mice the transcription of IKK2-CA or IKK2-DN together with the luciferase reporter gene was induced in the presence of doxycycline (Dox; Figure 1A). A clear advantage of this approach was that differentiation of acinar cells was completely normal while IKK2 activity was specifically modulated in adult mice.

Analysis of double-transgenic Ela.rtTAxIKK2-DN mice and littermate controls indicated a strong induction of the reporter gene after i.p. injection of Dox $(100 \mathrm{mg} / \mathrm{kg}$ body wt). This parenteral induction resulted in overall increased and more reproducible transgene expression compared with the conventional administration of Dox in the drinking water (data not shown). Expression of the transgene reporter luciferase was specifically detected in pancreas extracts of Ela.rtTA $\times$ IKK2-DN mice after induction by Dox, but not in a series of 20 nonpancreatic tissues tested and not in the absence of Dox (Figure 1B and data not shown). Although absolute expression levels differed between individual mice by as much as 5-fold, luciferase values in all Dox-induced Ela.rtTAxIKK2-DN 


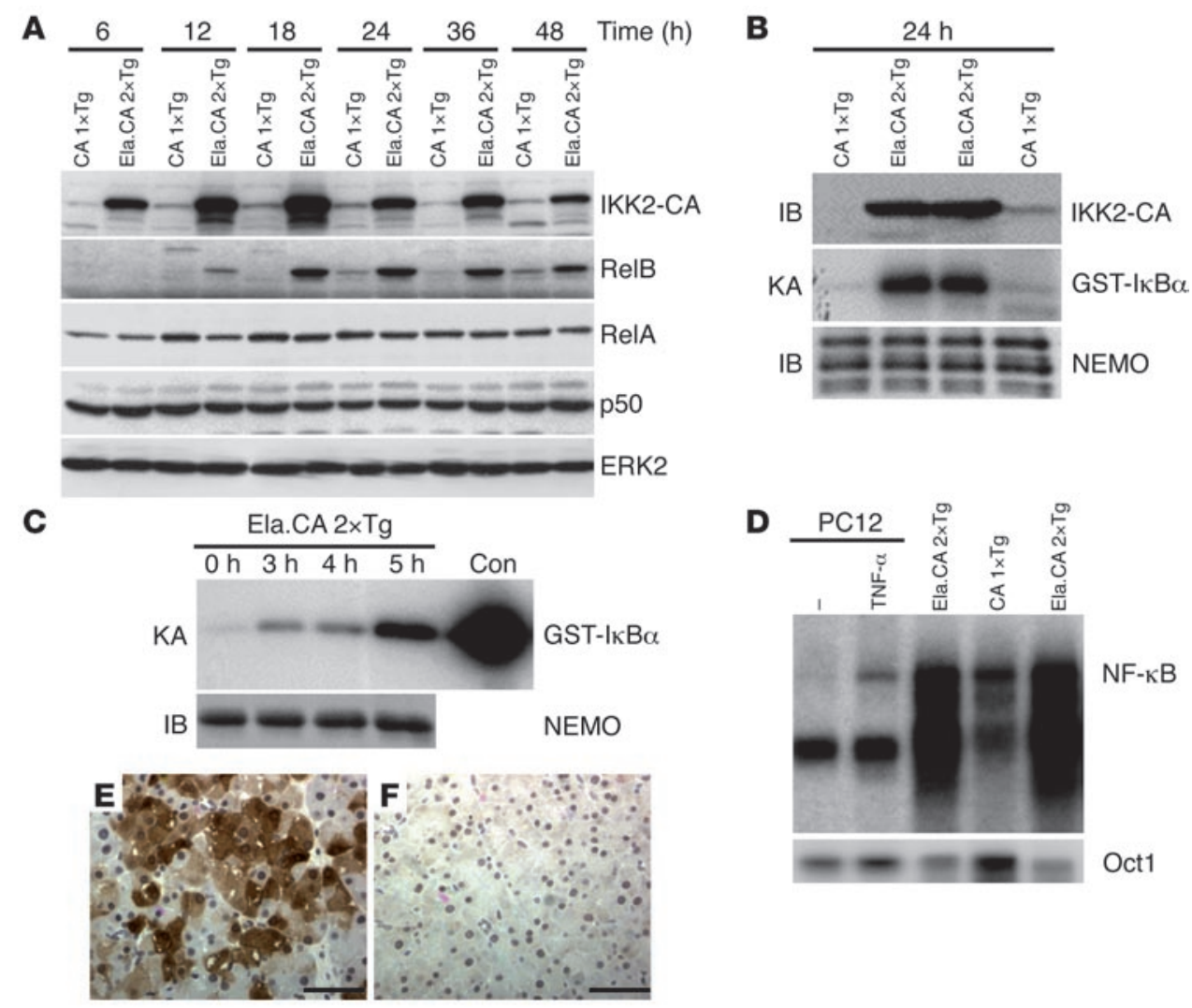

Figure 3

Expression and downstream signaling of IKK2-CA in transgenic mice. (A) Immunoblot of pancreatic extracts demonstrated overexpression of IKK2-CA in double-transgenic Ela.rtTA 1 IKK2-CA mice (Ela.CA $2 \times \mathrm{Tg}$ ) compared with single-transgenic IKK2-CA control mice (CA 1×Tg) between 6 and 48 hours after Dox injection. RelB expression was upregulated from 12 to 48 hours after Dox injection in Ela. rtTA×IKK2-CA mice, while RelA, p50, and ERK2 expression was unaffected. (B) Assay of kinase activity suggested activation of the kinase complex in pancreatic extracts from Ela.rtTAxIKK2-CA mice 24 hours after Dox. NEMO immunoblot (IB) confirmed equal precipitation of the IKK complex in Ela.rtTAxIKK2-CA and single-transgenic IKK2-CA extracts. (C) In vitro treatment of isolated acini with Dox results in rapid and strong induction of IKK kinase activity, NEMO immunoblot served as control for the equal precipitation. Recombinant IKK served as a positive control (Con). (D) EMSA of nuclear extracts of isolated acini from Dox-treated mice (18 hours) demonstrates increased nuclear NF- $\kappa B$ binding in Ela.rtTA $\times$ IKK2-CA mice compared with controls. Protein extracts from TNF- $\alpha$-treated pheochromocytoma (PC12) cells served as control for induced NF-кB activity. Oct1 DNA binding served as a control for the integrity of the nuclear extracts. (E and F) Immunohistochemical staining for IKK2 demonstrated patchy expression of the transgene in Ela.rtTA $\times$ IKK2-CA mice $(E)$ and absent staining in the controls $(F)$. Scale bars: $50 \mu \mathrm{m}$. genic IKK2-DN protein was detectable in single-transgenic IKK2-DN or uninduced double-transgenic Ela.rtTAxIKK2-DN mice. Kinase activity assays confirmed expression of a functional IKK2-DN protein (Figure 1E). In this experiment, isolated acini of single-transgenic IKK2-DN and double-transgenic Ela.rtTA×IKK2-DN mice injected with Dox were treated with cerulein in vitro. Cerulein treatment of acini isolated from single-transgenic IKK2-DN mice resulted in increased IKK2 kinase activity. This cerulein-inducible IKK2 kinase activity was markedly reduced in acini from Ela.rtTAxIKK2-DN mice (Figure 1E).

Importantly, induction of IKK2-DN expression in doubletransgenic Ela.rtTAxIKK2-DN mice by Dox did not have a detectable effect on these mice. No differences were observed in the macroscopic or microscopic morphologies of the pancreata of Ela.rtTAxIKK2-DN mice within 48 hours of induction by Dox compared with single-transgenic IKK2-DN controls or uninduced Ela.rtTA×IKK2-DN mice (Supplemental Figure 1A; supplemental material available online with this article; doi:10.1172/JCI30876DS1; and data not shown).

Expression of IKK2-DN attenuates the phenotype of cerulein-induced pancreatitis in vivo. Having demonstrated the ability to block IKK2 activity by IKK2-DN in pancreatic acini, we next sought to determine whether IKK2-DN expression would affect ceruleininduced pancreatitis. Therefore, we mice were at least 1,000-fold that of the background level. Singletransgenic IKK2-DN mice showed baseline luciferase activity before and after i.p. Dox application. In the absence of induction by Dox, luciferase values in the pancreata of Ela.rtTAxIKK2-DN mice likewise were essentially at baseline levels.

The expression of the transgene reporter was further analyzed by in vivo imaging of luciferase bioluminescence (Figure 1C). Luciferase activity was exclusively detected in the pancreatic regions of double-transgenic Ela.rtTAxIKK2-DN mice but not in other organs (e.g., thymus, heart, brain, or muscle) upon luciferin administration. This expression of the luciferase reporter gene suggests a high expression of the IKK2-DN transgene at the protein level. Figure 1D shows results of Western blot analysis of pancreatic extracts of Ela.rtTAxIKK2-DN mice 24 and 48 hours after induction by Dox compared with untreated controls. No trans- induced acute edematous pancreatitis with supramaximal doses of cerulein. Dox was injected 24 hours prior to the first cerulein injection to induce IKK2-DN expression (Figure 2A). In most experiments we used single-transgenic IKK2-DN mice to control for any effect of Dox treatment on the course of cerulein-induced pancreatitis. However, we also performed control experiments with Ela.rtTAxIKK2-DN mice not treated with Dox. These mice developed the same level of cerulein-induced acute pancreatitis as did single-transgenic IKK2-DN or wild-type mice. This further corroborates the tightness of the conditional gene expression system used (see Supplemental Figure 1, A and B). Single-transgenic IKK2-DN control mice developed morphological changes such as edema, infiltration of white blood cells, and tissue necrosis (Figure 2B). Consistent with earlier reports $(14,19)$, the leukocyte infiltrate primarily consisted of neutrophils. In addition, serum 


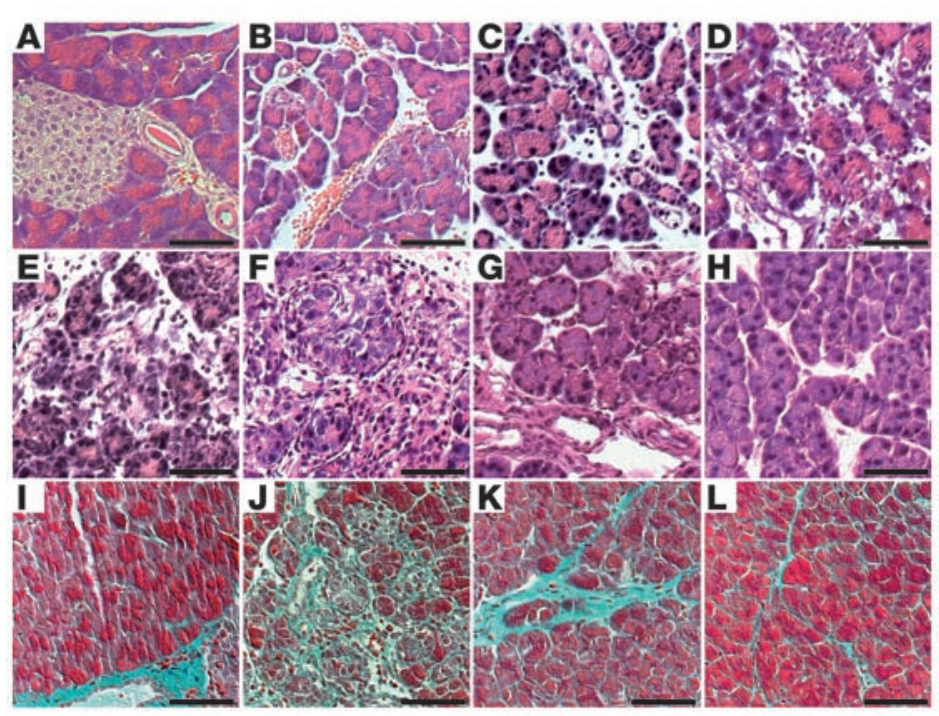

M

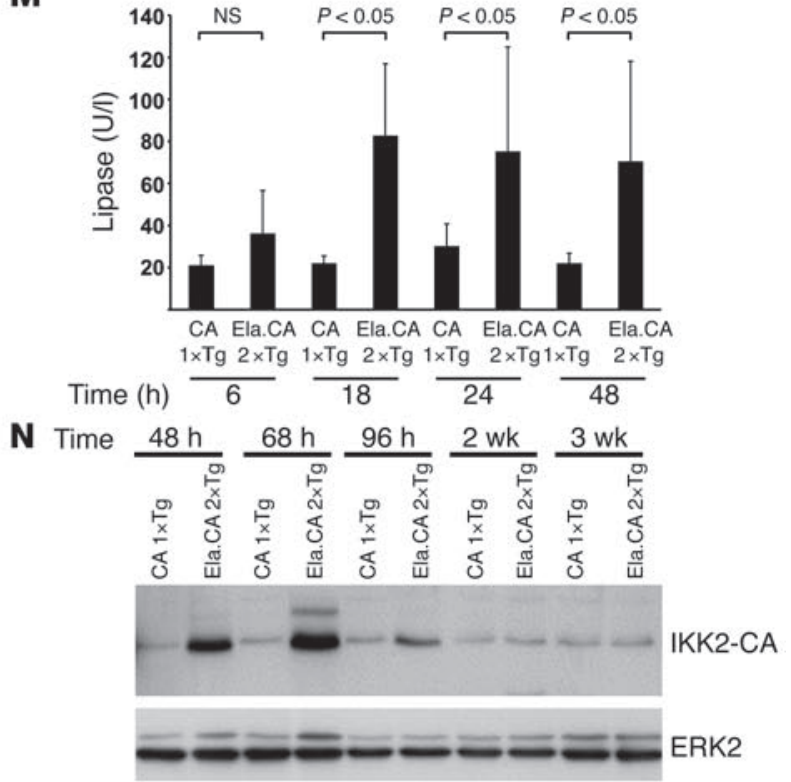

\section{Figure 4}

Overexpression of IKK2-CA induces pancreatitis. (A-H) Histological evaluation of pancreatic sections after Dox injection showed normal morphology in controls (A, 36 hours after Dox) and pancreatitis in Ela.rtTAxIKK2-CA mice (B-H). Early signs (B; 6 hours) included intralobular edema, followed by infiltration of inflammatory cells (C; 18 hours) and acinar cell necrosis after 48 hours (D). Extended acinar cell necrosis and intralobular deposits of extracellular matrix were evident 68 hours $(\mathbf{E})$ and 96 hours $(\mathbf{F})$ after Dox injection. Tissue regeneration was obvious 14 days $(\mathbf{G})$ and 21 days $(\mathbf{H})$ after Dox injection. (I-L) Masson-Goldner connective tissue staining of the control (I), 96 hours (J), 14 days (K), and 21 days (L) after Dox injection. (M) Serum lipase was increased in Ela.rtTAxIKK2-CA mice 6 to 48 hours after Dox injection. (N) Immunoblot confirmed prolonged IKK2-CA expression in Dox-induced Ela.rtTAxIKK2-CA mice up to 96 hours after Dox injection. ERK2 expression serves as loading control. Scale bars: $50 \mu \mathrm{m}$.

lipase levels dramatically increased (Figure 2C). This pathology is characteristic for the cerulein model of acute pancreatitis. In contrast, cerulein pancreatitis was ameliorated in the majority of Ela.rtTA $\times$ IKK2-DN mice. These mice showed much less affected morphology (Figure 2B), reduced serum lipase levels (Figure 2C), and an improved histology score (Figure 2D). Importantly, we found an excellent correlation of the transgene expression levels as evaluated by luciferase activity (data not shown) and IKK2-DN Western blot analysis (Figure 2E) - with the reduction of the pancreatitis phenotype. Mice with robust IKK2-DN expression were virtually completely protected from cerulein pancreatitis, whereas mice expressing low IKK2-DN levels still developed residual disease. In summary, our data indicate that inhibition of the IKK2/NF- $\mathrm{BB}$ signaling pathway protects animals from the characteristic tissue damage associated with the edematous pancreatitis induced by supramaximal stimulation with cerulein.

Expression of IKK2-CA induces a pancreatitis-like phenotype in vivo. Based on the findings described above, we next evaluated the effect of constitutive activation of the IKK $2 / \mathrm{NF}-\mathrm{KB}$ signaling pathway in double-transgenic Ela.rtTA $\times$ IKK2-CA mice in vivo. We wondered whether activation of this pathway exclusively in resident acinar cells would result in a pathological phenotype. As observed in Ela.rtTA $\times$ IKK2-DN mice, the Ela.rtTA $\times$ IKK2-CA mice showed highly inducible IKK2-CA expression only after Dox treatment (Supplemental Figure 2 and data not shown). Both the background expression levels and the levels of Dox induction were very similar to those seen with the IKK2-DN transgene. Injection of Dox caused rapid and sustained expression of the IKK2-CA protein (Figure 3A). After a single Dox injection, induction was evident at 6 hours, reached maximum levels at 18 hours, and lasted for more than 48 hours (Figure 3A). Kinase

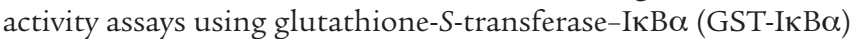
as a substrate demonstrated the function of the active IKK2 kinase (Figure 3B). We further confirmed the acinar cell-specific expression with immune complex kinase assays of isolated acini from Ela.rtTAxIKK2-CA mice treated in vitro with doxycycline (Figure 3C). Increased kinase activity was evident 3 hours after Dox treatment in vitro and further increased up to the 5-hour time point (Figure 3C). Furthermore, Western blot analysis showed time-dependent upregulation of NF- $\mathrm{KB}$ targets such as RelB, indicating that active IKK2 induces the NF- $\mathrm{B}$ signaling pathway in vivo (Figure 3A). The expression of the NF- $\kappa \mathrm{B}$ subunits $\mathrm{p} 50$ and RelA was not affected by IKK2-CA (Figure 3A). EMSA assays with nuclear extracts from isolated acini of mice treated with Dox in vivo demonstrated IKK2-CA-induced NF- $\mathrm{KB}$ activity (Figure 3D). Immunohistochemical staining for IKK2 confirmed that expression of the transgene was restricted to acinar cells (Figure 3, E and F). A patchy expression pattern was noted, indicating that inducible transgene expression is not homogeneous.

Activation of the IKK2/NF-KB signaling pathway by a single Dox injection resulted in massive tissue damage closely resembling the acute edematous pancreatitis observed in the cerulein model. We found an intralobular tissue edema 6 hours after Dox injection (Figure 4B). This phenotype resembled the changes observed 6 hours after induction of acute pancreatitis with cerulein (see Figure 2B). At 18 hours after Dox injection, tissue infiltration with mononuclear cells, predominantly granulocytes, was evident, and 24 hours after Dox injection, we found the first signs 


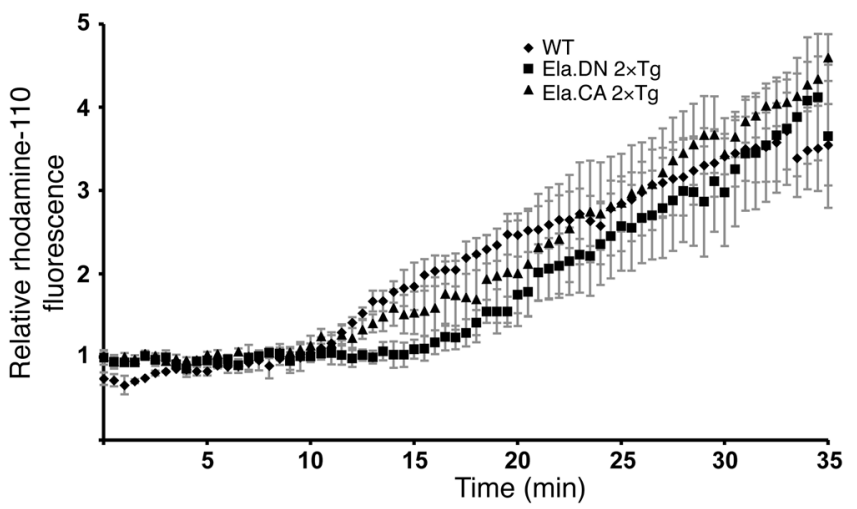

Figure 5

Activation of trypsin in acini is independent of IKK2-DN and IKK2-CA expression. Differential interference contrast and rhodamine-110 fluorescence images were collected throughout the equilibration period of isolated acini from wild-type, Ela.rtTAxIKK2-DN, and Ela.rtTAxIKK2-CA mice and after stimulation with supramaximal cerulein in vitro. Shown is quantitative evaluation of the relative fluorescence increase at the apical pole of at least 8 measurements for each genotype. Differences were not significant at 10,20 , and 30 minutes.

of tissue necrosis (Figure 4C and data not shown). These changes were not observed in untreated Ela.rtTAxIKK2-CA littermates, in Dox-injected single-transgenic IKK2-CA littermates, or in Ela. rtTA $\times$ IKK2-DN mice, excluding toxic effects of the injection itself (Figure 4A and data not shown). Serum lipase levels increased in Ela.rtTA×IKK2-CA mice over time; however, these levels did not reach the peak values observed in the cerulein model (compare Figure 4M with Figure 2C).

Evaluation of double-transgenic Ela.rtTA×IKK2-CA mice over time showed progressive destruction of the pancreas. Widespread tissue necrosis was observed 48 hours after induction by Dox (Figure 4D), and increased deposits of eosinophilic material were evident 68 and 96 hours after Dox injection (Figure 4, E and F), which suggested increased fibrosis. Accumulation of extracellular matrix was confirmed with Masson-Goldner connective tissue stain. Single-transgenic IKK2-CA mice (Figure 4I) showed sparse connective tissue in close proximity to ducts and vessels. A massive accumulation of extracellular matrix was evident 96 hours after Dox treatment (Figure 4J). We also analyzed the fibrosis sequence by immunohistochemistry, which revealed a strong increase in $\alpha$-smooth muscle actin, collagen I, and fibronectin staining 48 and 96 hours after a single Dox injection into Ela.rtTAxIKK2-CA mice (Supplemental Figure 3 and data not shown). Together these findings indicate severe tissue inflammation and destruction in Ela.rtTA $\times$ IKK2-CA mice resembling models of acute pancreatitis such as cerulein-induced pancreatitis. However, our model additionally induces massive fibrosis, which is not typically seen in the cerulein model of pancreatitis. Interestingly, morphologically normal areas of acinar cells reappeared within the heavily damaged organ 96 hours after induction by Dox. About 14 days after induction, regeneration of the acinar cells was evident; however, these acini were still surrounded with marked deposits of extracellular matrix, as assessed by $\mathrm{H} \& \mathrm{E}$ and Masson-Goldner staining (Figure 4, G and $\mathrm{K}$ ) as well as immunohistochemical staining for extracellular matrix proteins (Supplemental Figure 3). Regeneration was completed 3 weeks after the single Dox injection (Figure 4H).
However, a slight increase of connective tissue was still evident, as assessed by Masson-Goldner staining (Figure 4L). Expression of the IKK2-CA transgene was investigated in parallel to these morphological changes (Figure 4N). Substantial levels of IKK2-CA protein were detected up to 68 hours after induction by Dox, which was the time point of the most severe tissue damage (Figure 4E). At 96 hours after induction, IKK2-CA protein levels almost returned to baseline; however, it took 2-3 weeks in the absence of the IKK2-CA protein for the tissue damage to regenerate. Together, these findings demonstrate that expression of active IKK2 in acinar cells suffices to induce acute experimental pancreatitis.

Trypsin activation is independent of IKK2-DN and IKK2-CA expression in isolated acini in vitro. According to our current understanding, changes in the local calcium signaling and activation of trypsin are initiating steps of acute pancreatitis induced by supramaximal cerulein stimulation. To evaluate whether these initiating steps are impaired in Ela.rtTA×IKK2-CA mice, isolated acini were subject to supramaximal cerulein stimulation in vitro, and trypsin activation was analyzed. Double-transgenic Ela.rtTA $\times$ IKK2-CA and Ela.rtTAxIKK2-DN mice and littermate controls were injected with Dox either 24 hours (Ela.rtTAxIKK2-DN) or 12 hours (Ela.rtTAxIKK2-CA) before isolation of acini. After loading of freshly isolated acini with a trypsin-sensitive, rhodamine-coupled substrate, cells were incubated with supramaximal cerulein concentrations and monitored with high-resolution time-lapse fluorescence microscopy. Without addition of cerulein, no trypsin activation was evident over an incubation period of up to 30 minutes regardless of genotype (data not shown). Incubation with supramaximal concentrations of cerulein in vitro resulted in rapid cleavage of the trypsin substrate starting at the apical pole in acini isolated from littermate controls (data not shown). Quantitative analysis of trypsin activation in the region of interest is depicted in Figure 5. Comparable increases in kinetics and fluorescence intensity at the apical pole were observed in acini isolated from Ela.rtTAxIKK2-DN and Ela.rtTAxIKK2-CA mice, with no statistically significant differences. This indicates that the initiating steps in supramaximal cerulein stimulation are not dependent or otherwise influenced by IKK2-dependent NF-кB activation.

Expression ofIKK2-CA inducesexpression of TNF- $\alpha$. To determine the factors that mediate the inflammatory phenotype of Ela.rtTA $\times$ IKK2-CA mice after induction by Dox, we analyzed expression levels of several cytokines, chemokines, and inflammation markers by RT-PCR. Analysis was performed from 6 to 18 hours after Dox injection to exclude a major influence of the later appearance of inflammatory cells. We observed that granulocyte infiltration was evident 18 hours after induction (Figure 4C). Expression of $i N O S$, which served as a marker for the presence of infiltrating leukocytes, strongly increased at 12 and 18 hours after Dox injection (Figure 6F). Expression of Nfkbia, a transcriptional target of NF-кB, was upregulated in Ela.rtTA $\times$ IKK2-CA mice compared with singletransgenic IKK2-CA controls starting 6 hours after Dox injection; expression levels increased 4- to 5-fold compared with singletransgenic IKK2-CA controls after 12 and 18 hours (Figure 6A). Similarly, Icam 1 expression was dramatically induced in the Ela.rtTAxIKK2-CA mice 12 and 18 hours after Dox injection (Figure 6B). In contrast, we did not observe a major upregulation of $M c p 1$ expression in our model: an approximately 2-fold increase was observed 6 hours after induction. (Figure 6C). The mRNA expression of $I l 1 b$ increased predominantly at 18 hours after Dox injection, representing a late event in terms of the inflammatory 

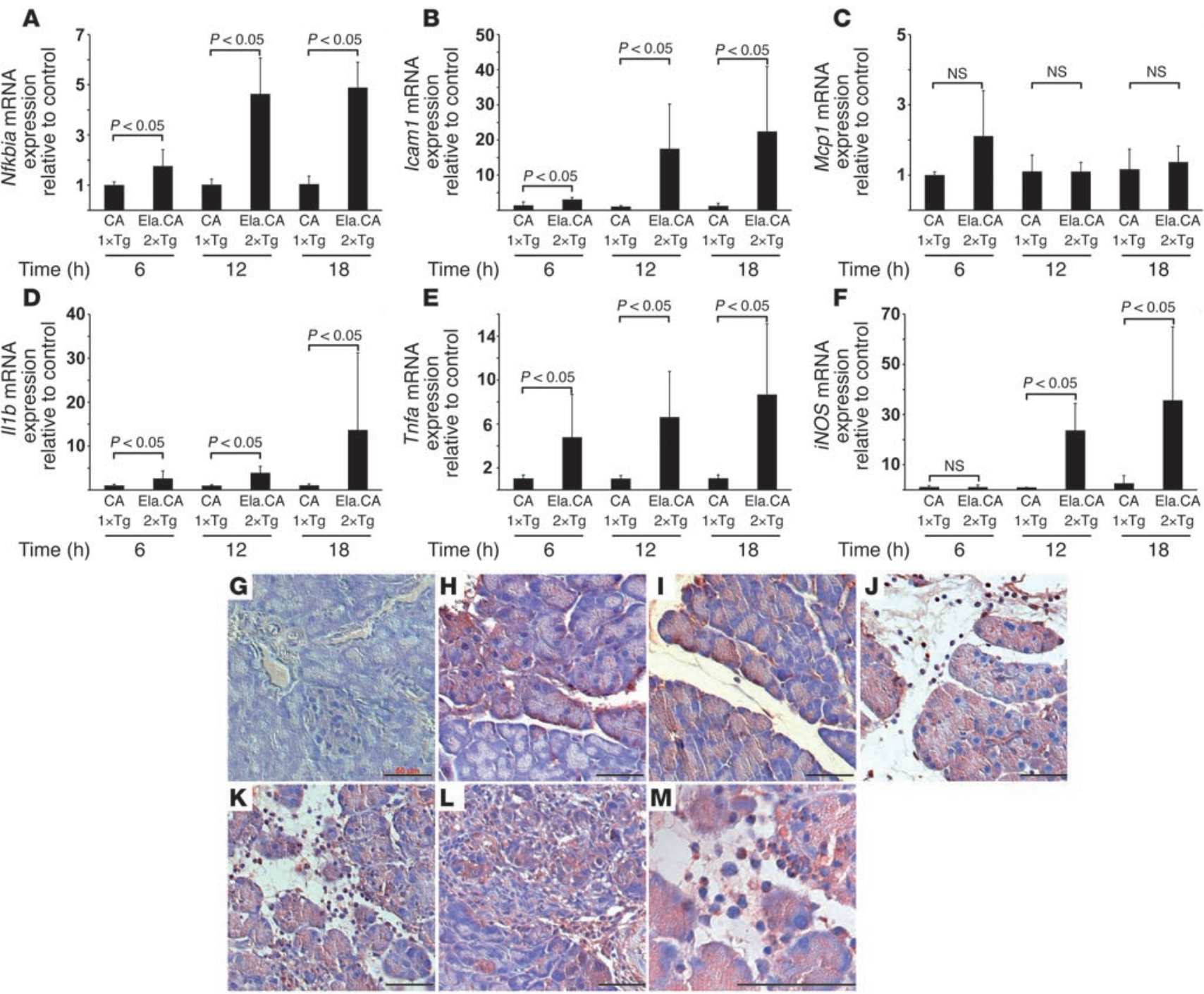

\section{Figure 6}

NF-kB-dependent target gene expression in the pancreata of IKK2-CA mice after Dox injection. (A-F) Relative expression of target mRNA in Ela.rtTAxIKK2-CA mice, as assessed by quantitative RT-PCR, was normalized to endogenous cyclophilin expression and expressed as fold change over controls. (A) Nfkbia was upregulated up to 4-fold 6-18 hours after Dox injection in Ela.rtTAxIKK2-CA mice compared with controls. (B) Icam1 expression was increased, in particular at 12 hours after Dox injection, up to 20 -fold that of controls. (C) Mcp1 mRNA was slightly increased 6 hours after Dox injection in Ela.rtTAxIKK2-CA mice. (D) I/1b was upregulated 18 hours after Dox injection. (E) Tnfa mRNA was induced in Ela.rtTAxIKK2-CA mice at levels 7-fold those of controls 18 hours after Dox injection. (F) iNOS mRNA, a marker for invasion of immune cells, was increased at 12 and 18 hours after Dox injection. Values represent mean of 4-5 individual mice measured in duplicate. (G-M) Sections of single-transgenic IKK2-CA (G) and Ela.rtTAxIKK2-CA mice (H-M) were stained with anti-TNF- $\alpha$. Patchy TNF- $\alpha$ expression was evident 6 hours after Dox treatment $(\mathbf{H})$ and became more prominent after 12 hours $(\mathbf{I})$ in the absence of invading leukocytes. Strong acinar staining and TNF- $\alpha$-positive leukocytes were evident $18(\mathrm{~J})$ and 48 (K and M) hours after Dox injection. (L) Acinar TNF- $\alpha$ staining decreased 96 hours after Dox injection. Scale bars: $50 \mu \mathrm{m}$.

response observed in the model (Figure 6D). Interestingly, Tnfa levels were markedly upregulated as early as 6 hours after induction (Figure 6E). At this stage we did not observe major tissue damage or infiltration of leukocytes (see Supplemental Figure 3). In order to demonstrate that acinar cells produce TNF- $\alpha$ in response to IKK2-CA expression, we performed immunohistochemical staining for TNF- $\alpha$ (Figure 6, G-M). At the 6-hour time point, patchy expression of TNF- $\alpha$ was evident in acinar cells (Figure $6, G$ and $H$ ). Consistent with the RT-PCR data, expression in acinar cells increased at 12, 18, and 48 hours after Dox treatment (Figure 6,
I, J, K, and M). Increased TNF- $\alpha$ levels were still evident after 96 hours, although the expression began to decline (Figure 6L). In addition to TNF- $\alpha$ expression in acinar cells, TNF- $\alpha$-positive leukocytes were also detected from 18 to 96 hours after Dox injection (Figure 6, J-L). This coexpression of TNF- $\alpha$ in both acinar cells and invading granulocytes was clearly evident in the higher-magnification image taken 48 hours after Dox injection (Figure 6M).

Inbibition of TNF- $\alpha$ ameliorates pancreatitis in IKK2-CA mice in vivo. It is well established that Tnfa is a target gene of the IKK2/NF- KB signaling pathway. In order to determine whether the induced TNF- $\alpha$ 
A

A Etan Etan
$\mathrm{mg} / \mathrm{kg}$ Dox

$(100 \mathrm{mg} / \mathrm{kg})$

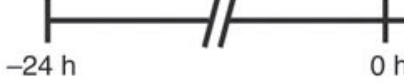

B

Dox Dox/Etan

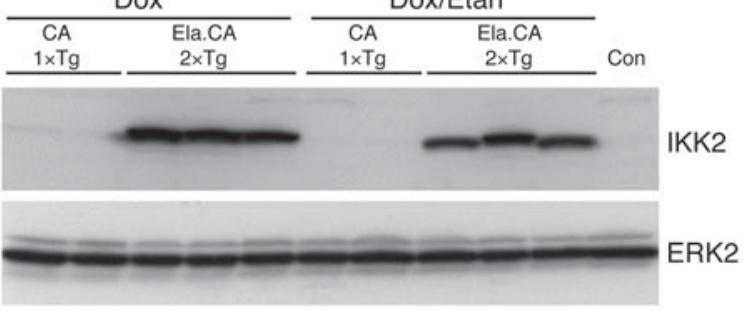

G
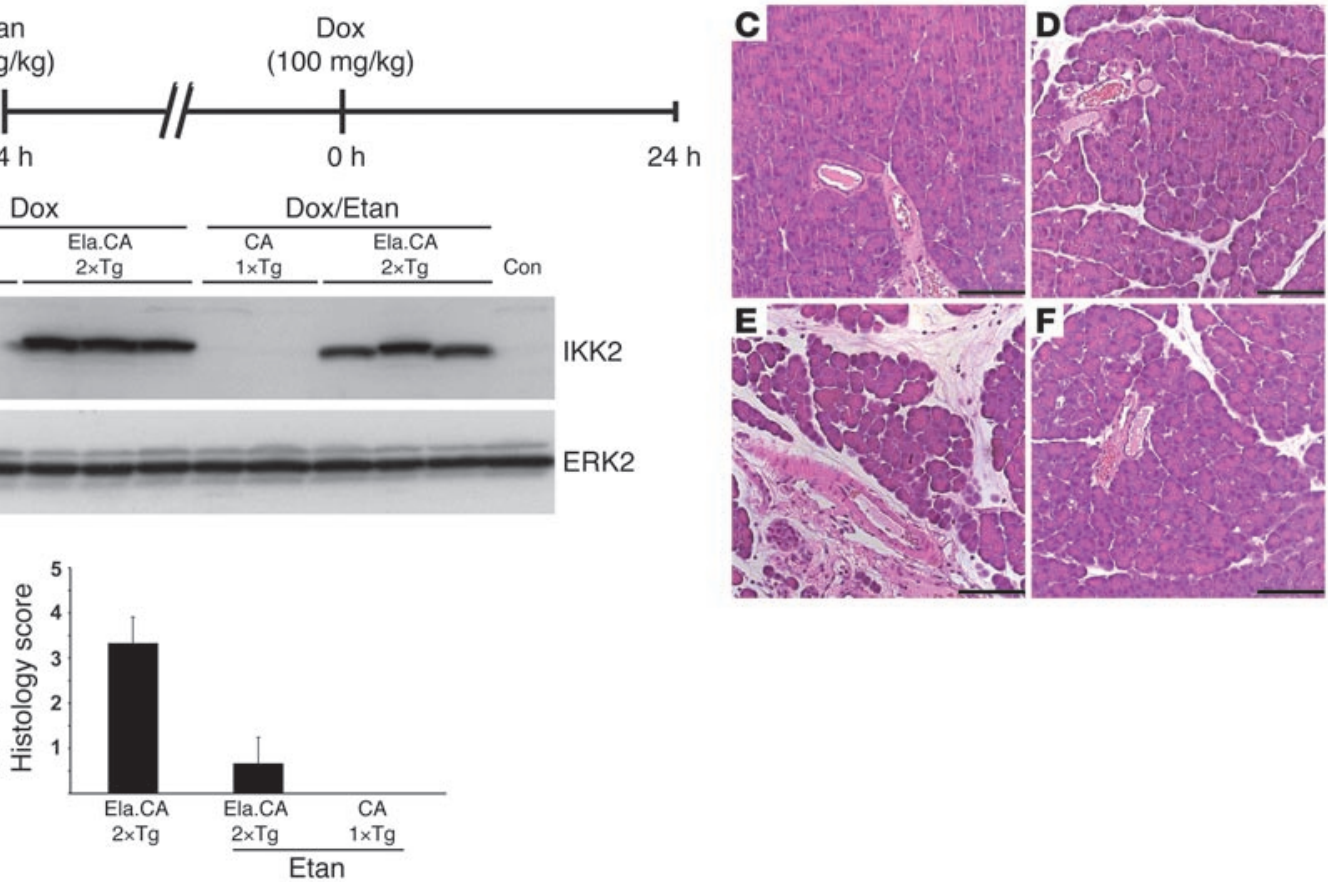

\section{Figure 7}

Etanercept attenuates IKK2-CA-induced pancreatitis in vivo. (A) Experimental design. Mice were pretreated with etanercept (Etan) 24 hours before injection of Dox and analyzed 24 hours after Dox injection. (B) Immunoblot for IKK2 showed comparable IKK2-CA levels in Ela.rtTAxIKK2-CA mice treated with etanercept and in untreated controls (Con). Single-transgenic IKK2-CA mice did not show relevant amounts of IKK2 upon immunoblot. ERK2 served as loading control. Etanercept treatment (C; control) and Dox injection to single-transgenic IKK2-CA mice (D; 24 hours after Dox) had no effect on pancreatic morphology. (E) Double-transgenic Ela.rtTAxIKK2-CA mice showed signs of pancreatitis 24 hours after Dox injection. (F) This phenotype was not observed in mice pretreated with etanercept. (G) Histology score ( $n=3$ mice per group).

expression immediately contributed to the pancreatitis phenotype observed in our mouse model, we blocked TNF- $\alpha$ action by treatment of the mice with etanercept, a soluble TNF receptor derivative. Double-transgenic Ela.rtTA×IKK2-CA mice were pretreated with etanercept 24 hours prior to Dox injection (Figure 7A). Etanercept treatment did not influence the protein expression level of IKK2-CA, as shown by Western blot analysis (Figure 7B). Etanercept alone had no effect on the morphology of pancreatic sections stained with H\&E (Figure 7C). Single-transgenic IKK2-CA mice and untreated Ela.rtTA $\times$ IKK2-CA mice did not show the obvious phenotype described above (Figure 7D and data not shown). However, etanercept pretreatment (Figure 7F) almost completely abolished the pancreatitis phenotype observed 24 hours after induction by Dox in Ela.rtTAxIKK2-CA mice (Figure 7E). This finding was further confirmed in quantitative scoring of the histological changes observed (Figure 7G). In summary, these data suggest that IKK2-CA-induced expression of TNF- $\alpha$ in acinar cells is a critical mediator in this model of pancreatitis.

\section{Discussion}

Our current understanding is that acute pancreatitis is the result of improper activation and release of active pancreatic enzymes to the interstitium followed by self digestion of the pancreas. This can result in multiple organ dysfunction caused by systemic inflammation. The underlying mechanisms of this complex disease are not well understood. However, most researchers agree that acute pancreatitis is initiated in the acinar cells and that the systemic organ failure is a consequence of synthesis and release of proin- flammatory cytokines and chemokines caused by local acinar cell damage $(6,7)$. Here we established a conditional system for acinar cell-specific modulation of IKK2 activity. This model allowed us to systematically evaluate and manipulate immanent acinar cell signaling pathways and shed light on the initial events of acute pancreatitis. We were further able to dissect local events and investigate the systemic responses responsible for the morbidity and mortality of severe acute pancreatitis.

We had previously demonstrated that conditional expression of the IKK2-CA allele under the control of CMV-driven rtTA, which is also predominantly expressed in the pancreas, aggravates cerulein-induced pancreatitis (21). This result is in perfect agreement with our new findings, yet the new mouse models clearly advance the previous study substantially. The model described in the current study provides several major advantages compared with the previous model. The CMV.rtTA-driven mouse does not show the extremely high acinar cell specificity of transgene expression. As a consequence, some contribution of IKK2 activation in other cell types like leukocytes could not be excluded. Additional major differences are expression levels and kinetics of induction. In the CMV.rtTAxIKK2-CA model, transgene expression was induced by addition of Dox to the drinking water. This resulted in a gradual increase of IKK2 expression over several days. Absolute levels of expression were markedly lower than the ones we achieved in the Ela.rtTA model with i.p. Dox injection, as assessed by luciferase values and intensity of signals in Western immunoblots (data not shown). This increased dynamic response resulted in a much more severe phenotype, namely, the induction of a complete pancreati- 
tis/fibrosis pathology with a single Dox injection. In addition, transgenic IKK2-DN expression levels were high enough to essentially block the endogenous IKK2 signaling pathway. This allowed us to elucidate the essential role of NF- $\mathrm{KB}$ activation in the cerulein-induced model of acute pancreatitis.

The combination of the Dox-responsive system under control of the proximal Ela with the well-characterized IKK2-DN and IKK2-CA allowed for highly efficient temporal and spatial modulation of the NF-кB pathway in vivo. We did not observe substantial expression of either transgene outside the pancreatic acini. This approach ensured that development and differentiation of the pancreas was completely unaffected. Only after Dox administration was signaling in mature acinar cells affected. Several biochemical analyses in our study showed that, as expected, inhibition or activation of the NF-кB signaling pathway was selectively achieved in acinar cells.

The inducible overexpression of IKK2-DN by itself had no measurable consequences for acinar cell physiology in the time frame analyzed. However, it largely attenuated cerulein-induced IKK2 kinase activity in vitro and ameliorated the course of acute, cerulein-induced edematous pancreatitis in vivo. Earlier experiments using pharmacological inhibitors of NF- $\mathrm{KB}$ showed downregulation of chemokine expression and an attenuation of acute, cerulein-induced pancreatitis in vivo (16, 23-25). However, conflicting results were found with the use of pharmacological inhibitors of NF-кB in the cerulein model. Steinle and coworkers observed increased severity of acute pancreatitis using pyrrolidine dithiocarbamate and N-acetyl-L-cysteine as NF- $\mathrm{KB}$ inhibitors (19). The major drawbacks of studies with pharmacological inhibitors are obviously (a) the lack of cell type specificity; (b) the inhibition of a broader range of targets; and (c) the possibility of toxic effects. Indeed, the specificity of the inhibitors used with respect to the $\mathrm{IKK} / \mathrm{NF}-\kappa \mathrm{B}$ pathway is questionable. More recent findings in NF-кB1-deficient mice also suggested an attenuation of cerulein-induced pancreatitis (26). However, the use of conventional knockout in this study does not enable the discrimination of local and systemic effects. It also does not identify the cell type in the pancreas, in which NF- $\kappa \mathrm{B}$ is critically active. The advantage of the tetracycline system applied in our study is the conditional temporal and spatial inactivation of NF- $\kappa \mathrm{B}$ during the course of cerulein pancreatitis. This controlled expression of IKK2-DN indicates that the observed amelioration of pancreatitis is specifically a result of decreased NF- $\kappa B$ signaling in acinar cells, because the NF- $\kappa B$ pathway in nonacinar cells is not immediately affected in the model.

However, the effects on inhibition of pancreatitis showed a certain level of variation. The most likely explanations for this variability are the patchy, nonhomogenous expression levels and differences in absolute expression levels between individual animals. Not all acinar cells showed induction of IKK2 expression (Figure 3E); furthermore, we observed variability in the levels of IKK2 and luciferase expression between individual mice. With respect to the latter, there was a striking correlation between transgene expression level and the extent of protection from acute pancreatitis. This suggests that incomplete suppression of IKK2 activity by the transgenic protein was responsible for the residual pancreatitis observed in some of the mice.

An alternative explanation for the incomplete protection from pancreatitis is that even with complete suppression of the NF-кB signaling pathway via the dominant-negative IKK2-DN kinase, a mild edematous pancreatitis is induced through hyperstimu- lation with cerulein. We showed that hyperstimulation with cerulein induced acinar trypsin activation even when IKK2 activity was blocked by expression of the dominant-negative kinase. Our results are consistent with an earlier report showing that adenovirus-mediated expression of $\mathrm{I} \kappa \mathrm{B} \alpha$ in acinar cells did not affect either basal or cholecystokinin-mediated (CCK-mediated) trypsinogen activation (27). Activation of trypsin might result in some degree of tissue damage; however, the local inflammation was largely suppressed. Trypsinogen activation by supramaximal doses of cerulein was previously shown to be a prerequisite for IKK-dependent NF- $\mathrm{KB}$ activation (28). Together these findings suggest that trypsin activation is an upstream event in pancreatitis induction in the cerulein model. This is further supported by the regular trypsin activation in acini isolated from IKK2 kinaseactive mice found in our study.

The open question is the link between early cellular events (e.g., trypsin activation), activation of the NF- $\mathrm{KB}$ signaling pathway, and systemic inflammation and how our experimental findings apply to the clinical situation in patients. Our data question the concept of self digestion as the culprit for acute pancreatitis. This common and widely accepted theory suggests that pancreatitis develops as a consequence of acinar injury or disruption, which permits the leakage of pancreatic enzymes such as active trypsin into the pancreatic tissue. These activated proteases in turn break down tissue and cell membranes, causing edema, vascular damage, and necrosis (29). Major experimental support for this concept came from in vitro and in vivo experiments based on supramaximal stimulation with CCK or cerulein. Furthermore, the discovery of mutations in the cationic trypsinogen gene that render patients more susceptible to acute and chronic pancreatitis illustrated the importance of this pathway (30). However, these mutations - or mutations affecting the inactivation of trypsin, such as the SPINK1 mutation - only apply to a minority of patients with acute pancreatitis (31). Despite the huge impact of the cerulein model on the discovery of major cellular events, it is unclear whether this model reflects the situation of acute pancreatitis in vivo.

Most cases of acute pancreatitis in patients are the result of alcohol consumption and obstructive bile stones. These inducers are poorly reflected in the current animal models of acute pancreatitis. Interestingly enough, several reports demonstrated that alcohol causes acinar cell NF-кB induction (32-34). The fact that activation of IKK2-CA was sufficient to induce edema and tissue necrosis indicates that acute pancreatitis can develop as a consequence of activation of cell-immanent signaling pathways in the absence of trypsin activation. Early signs in terms of edema were evident 6 hours after induction of IKK2-CA expression. Importantly, some aspects of this IKK2-induced pancreatitis are in fact more severe than in the cerulein model. Fibrosis is not a hallmark of ceruleininduced edematous pancreatitis. Furthermore, the tissue necrosis in IKK2-CA mice exceeds the tissue damage evident in ceruleininduced pancreatitis. Finally, the extended time period (96 hours) attests to the more severe phenotype of IKK2-CA mice.

Thus, the predominant role of trypsinogen activation in the cerulein model is the initiation of IKK/NF- $\mathrm{KB}$ activation, which does not necessarily contribute to the progression of acute pancreatitis and the degree of pancreatic acinar cell damage. Similarly, adenoviral expression of the active p 65 NF- $\mathrm{kB}$ subunit in acinar cells results in the induction of severe pancreatitis (20), which was also independent of trypsin activation. However, adenovirus infection represents an additional potentially inflammatory stimulus 
to the cells in the pancreas and is not specific for acinar cells. Here we showed that the sole expression of active IKK2-CA selectively in acinar cells was sufficient to induce pancreatitis.

But what links pancreatic injury to uncontrolled systemic inflammation, the major cause of morbidity and mortality of acute pancreatitis? Although we cannot conclusively answer this question, our data hint at a potential mechanism. We had previously shown that moderate IKK2 activation in the pancreas induces infiltration of mononuclear cells via the induction of proinflammatory cytokines (21). This system differs from the current experimental design in terms of the cellular context of IKK2-CA expression and its expression level. Strong and selective induction of IKK2, as achieved in the current report, resulted in rapid and stronger upregulation of the proinflammatory cytokine TNF- $\alpha$. This increased Tnfa expression occurred prior to the invasion of inflammatory cells in acinar cells, as assessed by histological and immunohistochemical analyses and $i N O S$ expression. This is consistent with earlier reports demonstrating the critical role of $\mathrm{NF}-\kappa \mathrm{B}$ in CCK/cerulein-induced expression of chemokines and proinflammatory cytokines $(26,35)$. In contrast, upregulation of $I l 1 b$ was a late event, indicating that this cytokine is a response to the invading leukocytes or is produced by these cells. Furthermore, the upregulation of Icam 112 hours after Dox injection is a consistent finding in experimental pancreatitis (36). In ICAM-1deficient mice, reduced severity of cerulein-induced pancreatitis has previously been reported (37).

The role of TNF- $\alpha$, a proinflammatory cytokine, is well recognized in experimental pancreatitis models (15, 38-40). TNF- $\alpha$ receptor-deficient mice develop less severe pancreatitis in response to cerulein hyperstimulation (ref. 18 and data not shown). Consistent with these results, we ameliorated IKK2-CAinduced pancreatitis at early stages by the injection of the TNF- $\alpha$ inhibitor etanercept. However, this blocking was not complete at later stages. One straightforward explanation for this effect is redundancy of ligands and receptors of the immune system. Indeed, targeting a single factor either in genetically modified animals or though pharmacological inhibition has not been proven sufficient to completely prevent the occurrence of pancreatic or distant organ injury (41).

In conclusion, we have established a highly efficient model that allowed for temporal and spatial manipulation of the NF- $\mathrm{KB}$ signaling pathway in the pancreas. We provided strong evidence for the pivotal role of this signaling pathway for the induction of acute pancreatitis and demonstrated that transcriptional regulation of proinflammatory cytokines by NF- $\mathrm{KB}$ in acinar cells is apparently sufficient to induce all subsequent events, resulting in a massive pathology including edema, leukocyte infiltration, and tissue necrosis and finally causing fibrosis. To our knowledge, this is the first report demonstrating that mere activation of this signaling pathway in a certain cell type is sufficient to trigger a full-blown pathological response.

\section{Methods}

Generation of transgenic mice and treatments. The rat proximal Ela promoter fragment $(0.2 \mathrm{~kb})$ was released by restriction digestion with SalI and BamHI from plasmid E0.2hGH (carrying the proximal rat elastase promoter fused to a genomic fragment of the human growth hormone gene) (42) and subcloned into $\mathrm{pBS}(\mathrm{KS}+)$ digested with SalI and BamHI. A BamHIXhoI fragment (in which BamHI was blunt ended) derived from this vector was cloned into pUHrT 61-1 previously cleaved with EcoRI-XhoI (in which
EcoRI was blunt ended) in place of the cytomegalovirus promoter (43). The resulting plasmid was designed as Ela-rtTA-M2. Cotransfection of AR42J with Ela-rtTA-M2 and the PBI-L tetracycline vector (Clontech) resulted in high luciferase expression in response to Dox.

Transgenic mice were generated by microinjection of pronuclei (MNRI outbred) with HindIII-PvuI fragment released from the Ela-rtTA-M2 vector following standard procedures. Seven transgenic founder mice (lines 1-7) were identified by PCR of genomic tail DNA as described previously (44). These founder mice were crossed to luciferase-(tetO) ${ }_{7}-\mathrm{IKK} 2-\mathrm{DN}$ indicator mice carrying the luciferase gene and IKK2-DN under the control of a bidirectional $\mathrm{tTA} / \mathrm{rtTA}$-responsive promoter to characterize the tissue-specific expression of Ela.rtTA and the potential of rTA-controlled transcription. Double-transgenic Ela.rtTA $\times$ IKK2-DN mice were exposed to Dox in $1 \%$ sucrose supplied as drinking water for 1 week before luciferase activity was determined in various organs. The founder line Ela.rtTA-5 showing the highest luciferase activity in the pancreas upon Dox application was used in further studies. To achieve IKK2-CA and IKK2-DN expression in acinar cells of the pancreas, luciferase-(tetO) ${ }_{7}-\mathrm{IKK} 2-\mathrm{CA}$ and luciferase-(tetO) $7^{-}$ IKK2-DN mice (22) were crossed to the Ela.rtTA-5 line. Double-transgenic Ela.rtTAxIKK2-CA and Ela.rtTAxIKK2-DN mice were injected with Dox $100 \mathrm{mg} / \mathrm{kg}$ i.p. at different time points before analysis.

Secret analog-induced pancreatitis was achieved by hourly i.p. injection of cerulein at a total concentration of $100 \mu \mathrm{g} / \mathrm{kg}$. Mice were sacrificed 6-18 hours after the first cerulein injection as described previously (19).

The TNF- $\alpha$ inhibitor etanercept was administrated by i.p. injection $(7 \mathrm{mg} / \mathrm{kg})$ 24 hours prior to Dox treatment. Etanercept is a soluble fusion protein composed of the extracellular domain of the p $75 \mathrm{TNF}$ receptor attached to the Fc portion of IgG1 that acts as competitive inhibitor of TNF- $\alpha$.

Ela.rtTAxIKK2-DN mice pretreated with Dox 24 hours prior to examination were injected i.p. with D-luciferin $(100 \mathrm{mg} / \mathrm{kg})$ for imaging of luciferase bioluminescence in vivo. Mice were placed into a light-tight chamber, and light emission was detected as photon counts ( 2 minutes' measurement beginning 10 minutes after luciferin injection) by an intensified charge-coupled device (ICCD) camera (Hamamatsu Aequoria System). Images were processed with the Wasabi software package (Hamamatsu Aequoria System). Mice without luciferin injection and Dox-untreated mice served as controls. All experiments were reviewed and approved by the Regierungspräsidium Tübingen.

Preparation of tissue specimens, histology, and immunohistochemistry. Mice were killed by either cervical dislocation or decapitation. Serum samples, tissue specimens for histology and immunostaining, and snap-frozen tissue for biochemical analysis were prepared following standard procedures. H\&E- and Masson-Goldner trichrome-stained sections were evaluated in a blinded fashion by an observer familiar with pancreatic pathology for the presence of infiltrating leukocytes, edema, and acinar cell necrosis. Morphological alterations were graded for the degree of inflammation, necrosis, and edema using a scale of $0-4$ as described previously (45). The sum of the single features was used to build the histology score, resulting in a range of 0 (normal pancreas) through 12 (complete destruction of the pancreas).

Immunohistochemistry was performed with the $\mathrm{ABC}$ staining kit (Vector Laboratories) using anti- $\alpha$-smooth muscle actin (Roche Diagnostics), anti-fibronectin (BIOMOL), anti-collagen I (Millipore), anti-TNF- $\alpha$ (Santa Cruz Biotechnology Inc.), anti-CD45-LCA (BD Biosciences - Pharmingen), anti-cytokeratin 8/18 (Progen Inc.), anti-mouse ki67 (Dako), and anti-IKK2 (Cell Signaling Technology Inc.) as primary antibody on paraffin sections as described previously (44).

Protein extraction, Western immunoblotting, EMSA, and immune complex kinase assay. Tissue samples were homogenized under liquid nitrogen using a proper pestle and mortar. The resulting tissue powder was used to prepare total protein extracts by freeze-thaw lysis as follows. The homogenized tis- 
sue was resuspended in 3 packed volumes of buffer $\mathrm{C}$ (20 mM HEPES, $25 \%$ glycerol, $0.42 \mathrm{M} \mathrm{NaCl}, 1.5 \mathrm{mM} \mathrm{MgCl} 2,0.2 \mathrm{mM}$ EDTA, 1 mM DTT, $1 \mathrm{mM}$ PMSF, and protease inhibitor cocktail, complete mini; Roche Diagnostics) and subjected to 3 cycles of freezing in liquid nitrogen and subsequent thawing on ice. After centrifugation, the supernatant was used as total protein extract and analyzed for luciferase activity. Specific luciferase activities were calculated as relative light units per microgram of protein.

For Western blotting, 50-100 $\mu$ g protein extract was separated by SDS-PAGE, transferred onto PVDF membranes, probed with specific antibodies, and developed by enhanced chemiluminescence. The following antibodies, all from Santa Cruz Biotechnology Inc., were used: anti-RelA (catalog no. sc-372), anti-RelB (catalog no. sc-226), anti-p50/p105 (catalog no. sc-114X), antiIKK $\alpha / \beta$ (catalog no. sc-7607), and anti-Erk2 (catalog no. sc-154). The preparation of cytoplasmic and nuclear extracts was performed on isolated acini. Acinar cells were washed twice in PBS and incubated for 15 minutes at $4{ }^{\circ} \mathrm{C}$ in 5 packed cell volumes of buffer A (10 mM HEPES, $1.5 \mathrm{mM} \mathrm{MgCl}_{2}, 10 \mathrm{mM}$ $\mathrm{Kcl}, 1 \mathrm{mM}$ DTT, $1 \mathrm{mM}$ PMSF, and protease inhibitor cocktail, complete mini; Roche Diagnostics) supplemented with trypsin inhibitor. Swollen cells were then aspirated 10 times with a 26-gauge needle. Nuclei were pelleted and washed twice with buffer A. Nuclear proteins were extracted for 1 hour in 2 packed cell volumes of buffer $\mathrm{C}$ supplemented with trypsin inhibitor; after centrifugation, the supernatant was used as nuclear extract. The supernatant from the first nuclear spin was supplemented with $10 \%$ glycerol and centrifuged, and the resulting supernatant was used as cytoplasmic extract.

For EMSA, nuclear protein extracts $(5 \mu \mathrm{g})$ were incubated for $20 \mathrm{~min}$ utes at room temperature with $3 \mu \mathrm{g}$ poly $\mathrm{dI} / \mathrm{dC}$ and $10 \mu \mathrm{g}$ BSA in buffer containing $50 \mathrm{mM} \mathrm{NaCl}, 1 \mathrm{mM}$ DTT, $10 \mathrm{mM}$ Tris-HCl, $1 \mathrm{mM}$ EDTA, 5\% glycerol, and radiolabeled double-stranded oligonucleotides containing a consensus NF-кB site or Oct-specific site. The formed DNA-protein complexes were then separated from free oligonucleotides on a native $4 \%$ polyacrylamide gel. To control activation of NF- $\mathrm{\kappa B}$ protein extracts from pheochromocytoma (PC12) cells treated with TNF- $\alpha$ (40 ng/ml final concentration, 30 minutes) were included in the EMSA experiments. PC12 cells were cultivated as described previously (46).

IKK kinase assays were essentially performed as described previously (46). After lysing homogenized pancreatic tissue or isolated acini in Triton lysis buffer, immunoprecipitation was performed with $0.5 \mathrm{mg}$ of cleared lysate using a mixture of equal parts IKK1/2- and NEMO-specific antibodies $(0.4 \mu \mathrm{g}$ each, catalog no. sc-7607 and sc-7330; Santa Cruz Biotechnology Inc.). Kinase reaction was performed in kinase buffer supplemented with $500 \mathrm{ng}$ recombinant GST-IкBa substrate in the presence of $10 \mu \mathrm{Ci}$ $\mathrm{p}^{32}$-ATP for 30 minutes at room temperature. Reaction was stopped by boiling in Laemmli buffer at $95^{\circ} \mathrm{C}$ for 5 minutes. Immunoprecipitates were separated by SDS-PAGE and blotted to PVDF membranes. Activity was detected using Hyperfilm (Amersham Biosciences). Membranes were probed with a monoclonal NEMO-specific antibody (catalog no. 611307; BD Biosciences - Pharmingen) to analyze for equal loading.

Preparation of pancreatic acini and in vitro trypsin activation. Pancreatic acini were prepared after an overnight fast by collagenase digestion, and trypsin activity in intact, living acini was quantitated as previously reported (47). In short, freshly prepared acini were suspended in HEPES-buffered medium, equilibrated for 30 minutes, loaded with the trypsin-sensitive dye (CBZ-IlePro-Arg)2-rhodamine- 110 (10 mmol/1; Invitrogen) for 30 minutes, transferred to an incubation chamber at $37^{\circ} \mathrm{C}$, stimulated with supramaximal doses of cerulein $(10 \mathrm{nM})$ after an additional equilibration of 5 minutes, and subjected to time-lapse (frames every 30 seconds) high-resolution fluorescence microscopy for up to 45 minutes. Trypsin activation was quantitated as relative increase of the rhodamine- 110 fluorescence in an area of interest over the apical pole of individual acinar cells. Figure 5 summarizes the mean of at least 8 experiments.

Isolation of RNA, reverse transcription, and real-time RT-PCR. Snap frozen pancreatic tissue was pulverized in liquid nitrogen and total RNA was extracted using the NucleoSpinKit (Machery-Nagel). First-strand cDNA was synthesized from $5 \mu \mathrm{g}$ total RNA using oligo-dT primers (18 mer) and M-MLV reverse transcriptase (Promega). The method of real-time PCR quantification after reverse transcription of the mRNA has been described in detail (44). Target mRNA level was normalized to the cyclophilin level and expressed as fold change compared with the wild-type control. Primer sequences for the amplification of Tnfa, Il1b, iNOS, Icam1, Mcp1, Nfkbia, and cyclophilin are provided in Supplemental Table 1.

Statistics. Serum lipase levels, mRNA levels, histology scores, and relative increase in rhodamine-110 fluorescence were expressed as mean and SD. Differences were evaluated for statistical significance by the Mann-Whitney-Wilcoxon test. A $P$ value less than 0.05 was considered significant.

\section{Acknowledgments}

This work was supported in part by Deutsche Forschungsgemeinschaft grant SFB518/A10 (to M. Wagner) and by the Fonds der Chemischen Industrie (to T. Wirth). We thank U. Möhnle, U. Leschik, and B. Ries for excellent technical support.

Received for publication November 7, 2006, and accepted in revised form March 20, 2007.

Address correspondence to: Thomas Wirth, Institute of Physiological Chemistry, Ulm University, Albert-Einstein-Allee 11, Ulm 89081, Germany. Phone: 49-0-731-50023270; Fax: 49-0-73150022892; E-mail: thomas.wirth@uni-ulm.de.

Tamara Aleksic's present address is: Weatherall Institute of Molecular Medicine, John Radcliffe Hospital, Cell Signaling Group, Oxford, United Kingdom.

Christoph K. Weber's present address is: Department of Gastroenterology, Sonnenhof, Bern, Switzerland.

Bernd Baumann, Martin Wagner, and Tamara Aleksic contributed equally to this work.
1. Li, Q., and Verma, I.M. 2002. NF-kappaB regulation in the immune system. Nat. Rev. Immunol. 2:725-734

2. Karin, M., and Greten, F.R. 2005. NF-kappaB: linking inflammation and immunity to cancer development and progression. Nat. Rev. Immunol. 5:749-759.

3. O'Neill, L.A. 2006. Targeting signal transduction as a strategy to treat inflammatory diseases. Nat. Rev. Drug Discov. 5:549-563.

4. Ghosh, S., and Karin, M. 2002. Missing pieces in the NF-kappaB puzzle. Cell. 109(Suppl.):S81-S96.

5. Bonizzi, G., and Karin, M. 2004. The two NF-kap-
paB activation pathways and their role in innate and adaptive immunity. Trends Immunol. 25:280-288.

6. Halangk, W., and Lerch, M.M. 2004. Early events in acute pancreatitis. Gastroenterol. Clin. North Am. 33:717-731.

7. Bhatia, M., et al. 2005. Pathophysiology of acute pancreatitis. Pancreatology. 5:132-144.

8. Raraty, M.G., Connor, S., Criddle, D.N., Sutton, R., and Neoptolemos, J.P. 2004. Acute pancreatitis and organ failure: pathophysiology, natural history, and management strategies. Curr. Gastroenterol. Rep. 6:99-103.

9. Adler, G., Hupp, T., and Kern, H.F. 1979. Course and spontaneous regression of acute pancreatitis in the rat. Virchows Arch. A Pathol. Anat. Histol. 382:31-47.

10. Merkord, J., et al. 1997. Acute interstitial pancreatitis in rats induced by dibutyltin dichloride (DBTC): pathogenesis and natural course of lesions. Pancreas. 15:392-401.

11. Hense, S., Sparmann, G., Weber, H., Liebe, S., and Emmrich, J. 2003. Immunologic characterization of acute pancreatitis in rats induced by dibutyltin dichloride (DBTC). Pancreas. 27:e6-e12.

12. Luthen, R., Grendell, J.H., Niederau, C., and Haussinger, D. 1998. Trypsinogen activation and 
glutathione content are linked to pancreatic injury in models of biliary acute pancreatitis. Int. J. Pancreatol. 24:193-202.

13. Yamaguchi, Y., Matsuno, K., Goto, M., and Ogawa, M. 1993. In situ kinetics of acinar, duct, and inflammatory cells in duct ligation-induced pancreatitis in rats. Gastroenterology. 104:1498-1506.

14. Algul, H., et al. 2002. Acute experimental pancreatitis and NF-kappaB/Rel activation. Pancreatology. 2:503-509.

15. Gukovskaya, A.S., et al. 1997. Pancreatic acinar cells produce, release, and respond to tumor necrosis factor- $\alpha$. Role in regulating cell death and pancreatitis. J. Clin. Invest. 100:1853-1862.

16. Grady, T., Liang, P., Ernst, S.A., and Logsdon, C.D. 1997. Chemokine gene expression in rat pancreatic acinar cells is an early event associated with acute pancreatitis. Gastroenterology. 113:1966-1975.

17. Brady, M., et al. 2002. Expression of the chemokines MCP-1/JE and cytokine-induced neutrophil chemoattractant in early acute pancreatitis. Pancreas. 25:260-269.

18. Denham, W., et al. 1997. Gene targeting demonstrates additive detrimental effects of interleukin 1 and tumor necrosis factor during pancreatitis. Gastroenterology. 113:1741-1746.

19. Steinle, A.U., Weidenbach, H., Wagner, M., Adler, G., and Schmid, R.M. 1999. NF-kappaB/Rel activation in cerulein pancreatitis. Gastroenterology. 116:420-430.

20. Chen, X., et al. 2002. NF-kappaB activation in pancreas induces pancreatic and systemic inflammatory response. Gastroenterology. 122:448-457.

21. Aleksic, T., et al. 2007. Cellular immune reaction in the pancreas is induced by constitutively active IkappaB kinase-2. Gut. 56:227-236.

22. Herrmann, O., et al. 2005. IKK mediates ischemiainduced neuronal death. Nat. Med. 11:1322-1329.

23. Ethridge, R.T., et al. 2002. Selective inhibition of NF-kappaB attenuates the severity of cerulein-induced acute pancreatitis. J. Am. Coll. Surg. 195:497-505.

24. Virlos, I., et al. 2003. Pyrrolidine dithiocarbamate reduces the severity of cerulein-induced murine acute pancreatitis. Shock. 20:544-550.
25. Gukovsky, I., Reyes, C.N., Vaquero, E.C., Gukovskaya, A.S., and Pandol, S.J. 2003. Curcumin ameliorates ethanol and nonethanol experimental pancreatitis. Am. J. Physiol. Gastrointest. Liver Physiol. 284:G85-G95.

26. Altavilla, D., et al. 2003. Attenuated ceruleininduced pancreatitis in nuclear factor-kappaBdeficient mice. Lab. Invest. 83:1723-1732.

27. Han, B., Ji, B., and Logsdon, C.D. 2001. CCK independently activates intracellular trypsinogen and NF-kappaB in rat pancreatic acinar cells. Am. J. Physiol. Cell Physiol. 280:C465-C472.

28. Tando, Y., et al. 2002. Induction of IkappaB-kinase by cholecystokinin is mediated by trypsinogen activation in rat pancreatic lobules. Digestion. 66:237-245.

29. Halangk, W., and Lerch, M.M. 2005. Early events in acute pancreatitis. Clin. Lab. Med. 25:1-15.

30. Whitcomb, D.C., et al. 1996. Hereditary pancreatitis is caused by a mutation in the cationic trypsinogen gene. Nat. Genet. 14:141-145.

31. Howes, N., Greenhalf, W., Stocken, D.D., and Neoptolemos, J.P. 2005. Cationic trypsinogen mutations and pancreatitis. Clin. Lab. Med. 25:39-59.

32. Satoh, A., Gukovskaya, A.S., Reeve, J.R., Jr., Shimosegawa, T., and Pandol, S.J. 2006. Ethanol sensitizes NF-kappaB activation in pancreatic acinar cells through effects on protein kinase C-epsilon. Am.J. Physiol. Gastrointest. Liver Physiol. 291:G432-G438.

33. Pandol, S.J., et al. 1999. Ethanol diet increases the sensitivity of rats to pancreatitis induced by cholecystokinin octapeptide. Gastroenterology. 117:706-716.

34. Gukovskaya, A.S., et al. 2004. Ethanol differentially regulates NF-kappaB activation in pancreatic acinar cells through calcium and protein kinase $C$ pathways. Am. J. Physiol. Gastrointest. Liver Physiol. 286:G204-G213.

35. Han, B., and Logsdon, C.D. 1999. Cholecystokinin induction of mob-1 chemokine expression in pancreatic acinar cells requires NF-kappaB activation. Am. J. Physiol. 277:C74-C82.

36. Zaninovic, V., Gukovskaya, A.S., Gukovsky, I., Mouria, M., and Pandol, S.J. 2000. Cerulein upregulates ICAM-1 in pancreatic acinar cells, which mediates neutrophil adhesion to these cells. Am. J.
Physiol. Gastrointest. Liver Physiol. 279:G666-G676.

37. Frossard, J.L., et al. 1999. The role of intercellular adhesion molecule 1 and neutrophils in acute pancreatitis and pancreatitis-associated lung injury. Gastroenterology. 116:694-701.

38. Vaccaro, M.I., et al. 2000. Pancreatic acinar cells submitted to stress activate TNF-alpha gene expression. Biochem. Biophys. Res. Commun. 268:485-490.

39. Ramudo, L., Manso, M.A., Vicente, S., and De Dios, I. 2005. Pro- and anti-inflammatory response of acinar cells during acute pancreatitis. Effect of $\mathrm{N}$-acetyl cysteine. Cytokine. 32:125-131.

40. Ramudo, L., Manso, M.A., Sevillano, S., and de Dios, I. 2005. Kinetic study of TNF-alpha production and its regulatory mechanisms in acinar cells during acute pancreatitis induced by bile-pancreatic duct obstruction. J. Pathol. 206:9-16.

41. Schafer, C., Tietz, A.B., and Goke, B. 2005. Pathophysiology of acute experimental pancreatitis: lessons from genetically engineered animal models and new molecular approaches. Digestion. 71:162-172.

42. Sandgren, E.P., Luetteke, N.C., Palmiter, R.D., Brinster, R.L., and Lee, D.C. 1990. Overexpression of TGF alpha in transgenic mice: induction of epithelial hyperplasia, pancreatic metaplasia, and carcinoma of the breast. Cell. 61:1121-1135.

43. Urlinger, S., et al. 2000. Exploring the sequence space for tetracycline-dependent transcriptional activators: novel mutations yield expanded range and sensitivity. Proc. Natl. Acad. Sci. U. S. A. 97:7963-7968.

44. Wagner, M., et al. 2001. A murine tumor progression model for pancreatic cancer recapitulating the genetic alterations of the human disease. Genes Dev. 15:286-293.

45. Rongione, A.J., et al. 1997. Interleukin 10 reduces the severity of acute pancreatitis in rats. Gastroenterology. 112:960-967.

46. Azoitei, N., Wirth, T., and Baumann, B. 2005. Activation of the IkappaB kinase complex is sufficient for neuronal differentiation of PC12 cells. J. Neurochem. 93:1487-1501.

47. Kruger, B., Albrecht, E., and Lerch, M.M. 2000. The role of intracellular calcium signaling in premature protease activation and the onset of pancreatitis. Am. J. Pathol. 157:43-50. 